Revista Tecné, Episteme y Didaxis: TED. Año 2014, Número Extraordinario. ISSN Impreso: 0121-3814, ISSN web: 2323-0126 Memorias, Sexto Congreso Internacional sobre Formación de Profesores de Ciencias. 08 al 10 de octubre de 2014, Bogotá

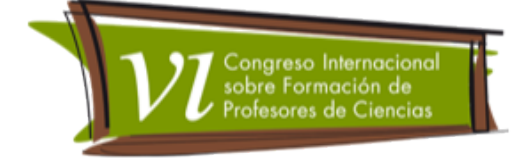

\title{
Modelos atômicos no ensino médio: abordagem clássica ou quântica?
}

Artuso, Rodrigo; Hussein, Fabiana Roberta Gonçalves e Silva

Categoria 2. Trabalho de Investigação

\section{Resumo}

Este artigo apresenta a análise de conteúdo em livros do Programa Nacional do Livro Didático para o Ensino Médio (Brasil), sobre a abordagem dos modelos atômicos clássico, semi-clássico ou quântico. Uma análise de conteúdo também é feita nas provas do ENEM, que são utilizadas como seleção para educação de nível superior no Brasil. Dos cinco livros analisados, dois continham abordagem sobre modelo atômico quântico, enquanto os demais não apresentaram nenhuma abordagem adequada sobre modelos atômicos quânticos. Além disso, um dos livros apresentou a mistura de modelos clássico, semi-clássico e quântico. Nas provas do ENEM observou-se a ausência do conteúdo modelos atômicos, apesar de constarem no Edital desse exame nacional.

\section{Palavras-chave}

Ensino Médio. Modelos Atômicos. Clássico. Quântico. Ensino-aprendizagem.

\section{Objetivo}

Analisar descritiva e qualitativamente como os modelos atômicos clássico, semi-clássico e quântico estão sendo apresentados nos livros didáticos do Programa Nacional do Livro Didático (PNLD) 2012, assim como avaliar como são cobrados conceitualmente esses modelos atômicos (MA) nas provas do Exame Nacional do Ensino Médio (ENEM).

\section{Marco Teórico}

É visível o avanço da ciência no último século, ainda mais quando relacionada à Química e à Física. Muito da evolução destas ciências se deve às observações que foram capazes de criar modelos teóricos que explicariam os fenômenos que rodeiam o ser humano. Devido à reflexões e tentativas de explicar o comportamento da matéria, muitos foram os modelos criados e é neste ponto que surgem os MA. É necessário que os alunos entendam que o modelo do átomo não foi algo descoberto, mas sim uma teoria criada pelo próprio homem, e que continua a se desenvolver sendo utilizada em 
Revista Tecné, Episteme y Didaxis: TED. Año 2014, Número Extraordinario. ISSN Impreso: 0121-3814, ISSN web: 2323-0126 Memorias, Sexto Congreso Internacional sobre Formación de Profesores de Ciencias. 08 al 10 de octubre de 2014, Bogotá

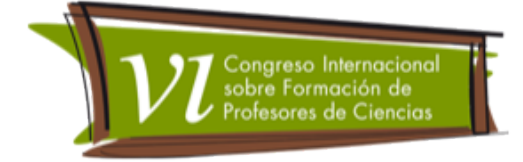

tecnologias modernas (GRECCA et al., 2001). Este desenvolvimento que ocorre nos últimos 20 anos é considerável para relevar a importância da inserção do MA quântico no Ensino de Química assim como no Ensino de Física, como defendido por Balthazar e Oliveira (2010).

Explicar os MA para os alunos não é tarefa fácil, para tanto os professores utilizam de generalizações, de analogias, expressões e metáforas, o que pode gerar concepções alternativas e má compreensão do conteúdo que, segundo Oliveira et al. (2013), não são observadas apenas nos alunos, mas também em alguns professores, o que pode interferir na maneira com que ensinam seus alunos.

Uma abordagem histórica do conteúdo é fundamental para que haja uma melhor aprendizagem, como defendido por alguns autores, como Farias (2004), Balthazar e Oliveira (2010), Moura (2013). Entretanto, é importante, antes de qualquer análise da abordagem histórica ou científica, fazer uma varredura de como os MA estão apresentados nos livros e quais apresentam maiores informações sobre os MA.

\section{Livros didáticos}

A principal fonte de pesquisa dos professores para preparar suas aulas é o livro didático (Lopes, 1992). No Brasil, os livros didáticos para todas as disciplinas do ensino médio são adquiridos e distribuídos pelo PNLD. É recomendado pelas Orientações Curriculares para o Ensino Médio (OCEM-2006) que haja, nos livros didáticos de Química (Tabela 1), uma compreensão do modelo RutherfordBohr e um reconhecimento do modelo quântico do átomo a partir de leis da Física. Demonstrando que existe uma intenção em diferenciar os modelos clássicos, semi-clássico e quântico, resta saber se os livros do PNLD seguem estes critérios. Nesse trabalho, classifica-se de clássicos os modelos de Dalton, Thomson e Rutherford, de semi-clássico como sendo o de Bohr, já que em suas expressões matemáticas inclui a quantização do momento angular, e quântico como sendo o modelo atual.

Tabela 1: Livros de Química analisados distribuídos pelo PNLD para Ensino Médio 2012.

\begin{tabular}{|c|c|c|c|}
\hline Identificação & Título & Autor(es) & Volume/Edição/Ano \\
\hline L1 & Química 1 & $\begin{array}{l}\text { Eduardo F. Mortimer e } \\
\text { Andréa H. Machado }\end{array}$ & Vol.1/1 ${ }^{a}$ Ed./2011 \\
\hline L2 & $\begin{array}{ll}\text { Química } & \text { na } \\
\text { Abordagem } & \text { do } \\
\text { Cotidiano } & \end{array}$ & $\begin{array}{l}\text { Francisco M. Peruzzo e } \\
\text { Eduardo L. do Canto }\end{array}$ & Vol. 1/ 4a Ed./2010 \\
\hline L3 & $\begin{array}{l}\text { Química 1 - Meio } \\
\text { Ambiente, } \\
\text { Cidadania }\end{array}$ & Martha Reis M. da Fonseca & Vol. 1/1 ${ }^{a}$ Ed./2011 \\
\hline
\end{tabular}


Revista Tecné, Episteme y Didaxis: TED. Año 2014, Número Extraordinario. ISSN Impreso: 0121-3814, ISSN web: 2323-0126 Memorias, Sexto Congreso Internacional sobre Formación de Profesores de Ciencias. 08 al 10 de octubre de 2014, Bogotá

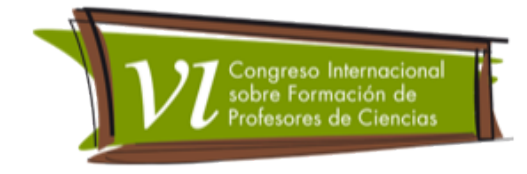

\begin{tabular}{|l|l|l|l|}
\hline \hline & Tecnologia & & \\
\hline L4 & Ser Protagonista & Julio C. F. Lisboa & Vol. 1/1 ${ }^{a}$ Ed./2010 \\
\hline L5 & Química Cidadã & Wildson Santos e GersónMól & Vol. 1/1 $1^{a}$ Ed./2010 \\
\hline
\end{tabular}

Um problema encontrado nos livros didáticos é que muitos livros acabam misturando os modelos de Bohr com o quântico, pois terminam um capítulo falando de núcleo e órbitas e iniciam outro falando de números quânticos e spin de elétrons, deixando a ideia de que os dois são um mesmo modelo (Farias, 2004).

\section{Provas do ENEM}

Criado em 1998, o ENEM tinha o objetivo de avaliar o desempenho de alunos ao fim do ensino médio, para constatar qual seria o nível educacional no país. A partir de 2009, a nota do ENEM passou a ser considerada por algumas universidades como o principal meio de ingresso. Tem como princípio evitar que assuntos sejam decorados e cobrar dos alunos o uso da lógica e que os mesmos sejam seres mais pensantes (Sousa Lima, 2011). É relevante estudar essas provas, por poderem regular como os conteúdos são abordados pelos livros didáticos e pelos professores nas escolas de todo o país, tendo em vista que são utilizadas por um grande número de instituições públicas e particulares.

\section{Metodologia}

Os livros didáticos e as provas do ENEM foram analisados descritiva e qualitativamente para investigar como são abordados os MA. Para tanto, utilizou-se a metodologia de análise de conteúdos de Bardin (2004). Buscou-se dar uma atenção maior para o modelo atômico quântico, pois é o responsável por caracterizar o átomo nos dias atuais.

Foram analisados os cinco livros aprovados pelo PNLD para o Ensino Médio 2012 (Tabela 1) que, apesar de serem poucos livros em comparação com a grande quantidade de exemplares no mercado, atingem grande parte das escolas públicas do Brasil por serem distribuídos de forma gratuita. Além dos cinco livros, foram analisadas seis provas do ENEM entre os anos de 2009 e 2013.

\section{Resultados e Discussões}

O livro L1 dedica todo o Capítulo 6 para os MA, o qual traz um prefácio contendo exemplos de propriedades da matéria que necessitam dos MA para serem compreendidos. Abordando um contexto histórico, o qual, segundo Farias (2004), é um método de fácil compreensão para os MA, os autores 
Revista Tecné, Episteme y Didaxis: TED. Año 2014, Número Extraordinario. ISSN Impreso: 0121-3814, ISSN web: 2323-0126 Memorias, Sexto Congreso Internacional sobre Formación de Profesores de Ciencias. 08 al 10 de octubre de 2014, Bogotá

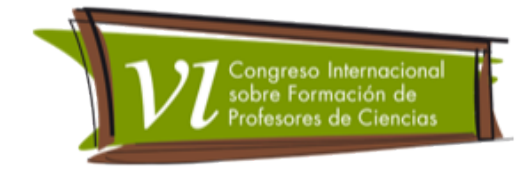

apresentam o modelo dos filósofos gregos e comentam sobre a ldade Média para posteriormente iniciar o modelo de Dalton. Seguindo cronologicamente a ordem, os autores desta obra apresentam os MA de Thomson, Rutherford e Bohr. O capítulo aborda teorias modernas falando sobre o comportamento dos elétrons, princípio da incerteza e orbital para que possa servir de base para explicar números quânticos, distribuição eletrônica e organização da tabela periódica.Esse livro dispõe de grande quantidade de informações sobre os MA e apresenta o modelo mais atual, como proposto pelas OCEM. Apesar de apresentar conceitos aprofundados dos MA e apresentar características quânticas, conforme este trabalho busca encontrar, Ll é muito pouco usado em Curitiba-PR, local em que esta pesquisa foi realizada, apesar de ter sido adquirido por algumas escolas nessa cidade. A não escolha deste exemplar pode ser ocasionada pelo conteúdo aprofundado e devido à dificuldade dos professores para interpretar estes textos, como observado por Sá et al. (2013).

O livro L2 dedica três capítulos para apresentar os MA, iniciando pelo capítulo 4, no qual consta o modelo de Dalton de forma sucinta. Antes de abordar o modelo de Thomson os autores discorrem, já no capítulo 5, sobre a natureza elétrica da matéria. Apresentam o modelo de Rutherford e em seguida 0 modelo de Bohr, Capítulo 6, após introdução das limitações do modelo de Rutherford e dos espectros eletromagnéticos. Este livro apresenta conceitos importantes para a compreensão dos modelos clássicos e semi-clássico, bem como suas aplicações para explicar algumas propriedades da matéria e de fazer a separação entre o modelo de Bohr e os subníveis de energia. Apesar de conter informações básicas para a compreensão de alguns fenômenos, tal como as ligações químicas, como estudado por Toma (1997), este livro não menciona qual o MA mais atual.

No livro L3 o conteúdo de MA se inicia no Capítulo 7 com conceitos de leis e teorias para, em seguida, inserir o modelo de Dalton. A continuação dos MA só é retomada no Capítulo 12, com o modelo de Thomson seguido pelo de Rutherford, fazendo abordagem sobre a natureza elétrica da matéria não comentando os raios catódicos. Este livro apresenta uma introdução ao eletromagnetismo, ao efeito dual do elétron e espectros atômicos para posteriormente apresentar o modelo de Bohr. A autora do livro organiza os MA de forma diferente aos demais, pois apresenta os modelos de acordo como eles são necessários para explicar fenômenos naturais, sendo essa uma metodologia muito interessante para o ensino de MA, pois faz com que esses sejam vistos com uma maior importância pelos alunos. Entretanto, a autora não indica qual modelo é o mais atual, nem apresenta separação entre os modelos clássicos, semi-clássico e quântico do átomo. 
Revista Tecné, Episteme y Didaxis: TED. Año 2014, Número Extraordinario. ISSN Impreso: 0121-3814, ISSN web: 2323-0126 Memorias, Sexto Congreso Internacional sobre Formación de Profesores de Ciencias. 08 al 10 de octubre de 2014, Bogotá

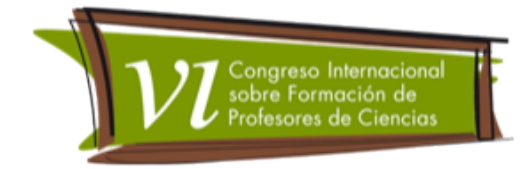

No Capítulo 7 do livro L4 encontra-se todo o conteúdo de MA. O prefácio possui exemplo da utilização dos modelos para se explicar as propriedades da matéria. Os filósofos gregos são lembrados no início do capítulo e segue-se a ordem histórica de cada um dos modelos, passando por Dalton, Thomson e Rutherford, cada uma com suas contribuições. Também apresenta o conteúdo sobre espectros eletromagnéticos para explicar o modelo de Bohr. Esse livro aborda o tema de MA de maneira fácil e direta, sem se aprofundar em cada modelo. Além da falta de aprofundamento no tema, o livro fala de distribuição eletrônica logo após abordar Bohr, podendo levar o leitor a crer que foi este cientista que descreveu os elétrons em subníveis de energia e que o seu modelo é aceito até os dias de hoje para explicar a estrutura eletrônica de todos os átomos, causando uma "mistura" dos MA (Farias, 2004).

Assim como o livro L1, O livro L5 dedica apenas o capítulo 5 para abordar O assunto de MA. Inicia-se o capítulo com um texto sobre a camada de ozônio e protetor solar. Após isso, fala-se do modelo de Dalton e para cada modelo posterior faz-se introdução de conceitos básicos para explicar cada um, como a natureza elétrica da matéria para o modelo de Thomson, a radioatividade para o modelo de Rutherford e seu experimento, e espectros eletromagnéticos para o modelo de Bohr. O livro traz uma seção para falar sobre modelo quântico e orbitais, especificando dessa forma qual o modelo mais atual para o átomo. Percebe-se a abordagem quântica do modelo atômico neste livro, apresentando de maneira aprofundada e ao mesmo tempo clara, por conter vários exemplos, também uma abordagem do efeito dual - partícula-onda do elétron, como estudada por Ramos e Silva (2012) neste mesmo livro. Apesar de grande quantidade de informações, este livro em comparação com os demais é o menos adquirido pelas escolas do Brasil, cerca de $6 \%$ do mercado (Moura, 2013).

Durante a finalização deste trabalho, encontrou-se na literatura da área uma análise mais completa dos MA nos livros do PNLEM 2006/2007 (Silva e Cunha, 2009). Investigando essa referência, foi possível comparar os livros do PNLD 2012 com relação aos dos PNLEM 2006/2007. Fica evidente a melhoria nas obras em 2012, devido às políticas voltadas à melhoria da educação e na escolha dos livros didáticos, ressaltando que alguns dos autores foram aceitos nesses dois Programas Nacionais do Livro para o Ensino Médio. Observa-se que - livro L1 manteve-se entre os mais destacados com uma abordagem adequada para os MA. Além disto, é importante destacar a evolução no livro L5 que passou a trazer o MA quântico em sua edição mais recente. 
Revista Tecné, Episteme y Didaxis: TED. Año 2014, Número Extraordinario. ISSN Impreso: 0121-3814, ISSN web: 2323-0126 Memorias, Sexto Congreso Internacional sobre Formación de Profesores de Ciencias. 08 al 10 de octubre de 2014, Bogotá

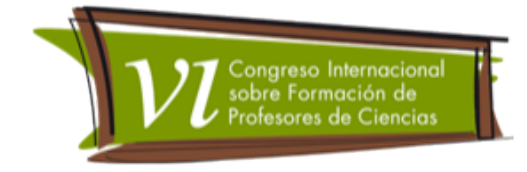

\section{Provas do ENEM}

A análise das provas do ENEM nos anos de 2009 a 2013 apresentou um resultado surpreendente que não era esperado diante da visão de ensino e aprendizagem dos autores deste trabalho, pois nenhuma das seis provas analisadas fez qualquer menção aos MA.

O ENEM busca evitar a fixação na memória do conteúdo sem significado e sem relações prévias, portanto pode-se criticar a não cobrança dos $M A$, pois esses são, junto com outros conteúdos estruturantes da Química, base da construção do conhecimento químico.

Verifica-se que o ENEM está se tornando o principal meio de entrada em universidades do Brasil e, perante a grande influência exercida por este exame, é possível que haja uma reforma nos Currículos Nacionais de Química (Marcelino e Recena, 2012). Entretanto, essa mudança poderia causar a retirada de conteúdos estruturantes de Química dos livros didáticos, um exemplo em que nos preocupa nesse trabalho seria os conteúdos referente aos Modelos Atômicos, pelo fato de não terem sido citados em nenhuma das provas analisadas nessa pesquisa.

\section{Conclusões}

Observa-se que todos os cinco livros trabalham de forma semelhante até o modelo atômico de Bohr, apesar de os livros L2 e L3 não citarem os filósofos gregos, o que já passaria a ideia de que o MA não é algo investigado, estudado, pensado ou proposto e sim algo descoberto. Além disso, apenas L1 e L5 citam o MA mais atual, falando de mecânica quântica, condizendo com as Orientações Curriculares e servindo de base para conhecimentos mais aprofundados como os propostos por autores como, Toma (1997), Balthazar e Oliveira (2010), Ramos e Silva (2012), os quais defendem uma abordagem quântica no ensino médio, assim como os autores deste trabalho.

Outro fato relevante é a de que os dois livros que melhor abordam o tema de MA (Ll e L5) são os de menor distribuição no mercado. Como são os professores das escolas que escolhem os livros, é muito provável que haja uma dificuldade também nos professores em interpretar os MA, o que, segundo Oliveira et al. (2013), acompanha os professores no seu processo de formação. Sem falar que não foi observado na Secretaria do Estado do Paraná, na opinião de alguns professores entrevistados, nenhuma formação para o uso didático destes livros do PNLD 2012, como também só recentemente que tem 
Revista Tecné, Episteme y Didaxis: TED. Año 2014, Número Extraordinario. ISSN Impreso: 0121-3814, ISSN web: 2323-0126 Memorias, Sexto Congreso Internacional sobre Formación de Profesores de Ciencias. 08 al 10 de octubre de 2014, Bogotá

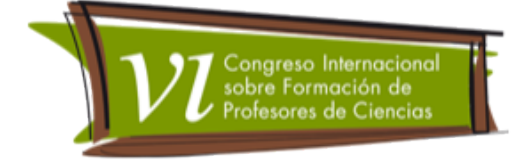

se observado nas ementas de cursos de licenciatura a análise de livros para o Ensino Médio no Brasil. A não existência de questões sobre os átomos e/ou estrutura eletrônica da matéria e/ou MA em provas de grande alcance no Brasil, para os alunos que querem fazer o ensino superior, como o ENEM, faz com que esse conteúdo acabe sendo deixado de lado pelos professores do Ensino Médio.

\section{Referências Bibliográficas}

Balthazar, W. F.; Oliveira, A. L. (2010). Partículas Elementares No Ensino Médio: Uma abordagem a partir do LHC. São Paulo. Ed. Livraria da Física.

Bardin, L. (2004). Análise do conteúdo. Ed. 3, pág. 223. Lisboa, PT.

Brasil. Ministério da Educação (MEC), Secretaria de Educação Básica. (2006). Orientações curriculares para o ensino médio, v. 2.

Farias, R. F. (2004). Para Gostar de Ler a História da Química Vol. 2. Campinas, SP: Ed. Átomo.

Greca, I. M.; Moreira, M. A.; Herscovitz, V. E. (2001) Uma proposta para o ensino de Mecânica Quântica. Revista Brasileira de Ensino de Física, Porto Alegre, v. 23, n. 4.

Lopes, A. R. C.(1992). Livros didáticos: obstáculo ao aprendizado da Ciência Química. I - obstáculos animistas e realistas. Quim. Nova, v. 3, n.15, págs. 254-261.

Marcelino, L. V.; Recena, M.C.P. (2012). Possíveis influências do novo ENEM nos currículos educacionais de química. Est. Aval. Educ., São Paulo, v. 23, n. 53, págs. 148-177.

Moura, C. B.; Guerra, A.(2013). Modelos atômicos em livros didáticos de química do PNLEM 2012: uma análise qualitativa à luz da história e filosofia da ciência. In: IX ENPEC, Águas de Lindoia, SP, Brasil. Atas.

Oliveira, M. E. S.; Brabo, J. N. C.(2013). Modelos atômicos de atuais e futuros professores de Química: teorias científicas ou representações sociais? In: IX ENPEC, Águas de Lindoia, SP, Brasil. Atas.

Ramos, L.C.; SILVA, J. L. P. B. (2012). Modelo quântico do átomo: uma análise do ensino das noções de quantum de uma grandeza e comportamento dual da energia e da matéria. In: XVI ENEQ, Salvador, BA, Brasil. 
Revista Tecné, Episteme y Didaxis: TED. Año 2014, Número Extraordinario. ISSN Impreso: 0121-3814, ISSN web: 2323-0126

Memorias, Sexto Congreso Internacional sobre Formación de Profesores de Ciencias. 08 al 10 de octubre de 2014, Bogotá

SÁ, C. S. S.; Moreira, B. C. M; Varjão, T. A. (2013). Modelização do átomo: implementando e avaliando uma proposta didática. Enseñanza de lasCiencias, v. extra, págs. 934-940.

Silva, J. L. P. B. ; CUNHA, Maria Bernadete de Melo (2009) . O modelo atômico quântico em livros didáticos de química para o ensino médio. In: VII ENPEC, Florianópolis, SC, Brasil.

Souza Lima, M. C. de. (2011). Resultados de Ingressantes no Ensino Superior via ENEM: Um Ensaio De Avaliação. Dissertação de Mestrado. Fundação Cesgranrio, RJ, Brasil.

Toma, H. E.(1997). Ligação Química - Abordagem Clássica Ou Quântica? Quim. Nova na Escola, v. 6, págs. 8-13. 